Bensing, J., Verheul, W. Towards a better understanding of the dynamics of patient provider interaction: the use of sequence analysis. Patient Education and Counseling: 2009, 75(2), 145146

\begin{tabular}{|l|l|}
\hline $\begin{array}{l}\text { Postprint } \\
\text { Version }\end{array}$ & 1.0 \\
\hline $\begin{array}{l}\text { Journal website } \\
\text { Pubmed link }\end{array}$ & $\underline{\mathrm{http}: / / \mathrm{dx} . \text { doi.org/10.1016/j.pec.2009.03.002 }}$ \\
\hline DOI & $\underline{10.1016 \text { ww.j.pec.2009.03.002 }}$ \\
\hline
\end{tabular}

This is a NIVEL certified Post Print, more info at http://www.nivel.eu

\title{
Towards a better understanding of the dynamics of patient provider interaction: The use of sequence analysis
}

\author{
JOZIEN BENSING, WILLIAM VERHEUL
}

NIVEL (Netherlands Institute for Health Services Research)

P.O. Box 1568, 3500 BN Utrecht, The Netherlands

Ever since, in the early eighties, Inui and Carter published their classic series of articles on doctor-patient interaction analysis [1] and [2], there is a recurrent debate on the most adequate strategies for analyzing the often complex interactions between patients and their health care providers. At that time, patient-provider communication was usually examined by presenting frequencies of coded communication behaviors and using correlation-based statistical techniques to analyze relations between those frequencies, thus ignoring the interactions between the two main players: the doctor (or nurse) and the patient. This led Inui and Carter to their provoking statement that most researchers reduced the medical encounter to a flat bundle of statistics, as if Hamlet would be described as "a play with 21 principal characters, a ghost, a group of players, and various numbers of lords, ladies, officers, soldiers, sailors, messengers, and attendants - one of whom is already dead, one of whom dies by drowning, one poisoned by drink, two by poisoned sword and one by poisoned sword and drink" [3]. A more vivid way to describe the lack of dynamics in patient-provider communication studies could hardly be given.

Qualitative studies were generally seen as the most adequate way of revealing the micro dynamics of patient-provider interaction. It is only fairly recently that researchers also started to use quantitative techniques to zoom in on the interaction between doctor and patient, for example by analyzing turn-taking [4], or applying sequence analysis on the coded data [5]. Sequence analysis, which is not a single statistical technique, but a body of questions about how social processes emerge and a collection of techniques to study those [6] - has recently become quite popular among health communication studies, as was shown by Zimmermann et al in their recent review [5]. Sequence analysis studies, other than frequency association studies, allow an understanding of the temporal relationship between events, focusing on interactions in terms of what precedes and follows specified target behaviour [5]. Strictly spoken, these methods do not permit causal inferences, just like it is the case in frequencybased association studies. However, there is no doubt that analysing the order of events may give a better idea of how the interaction between doctor and patient proceeds over time under influence of the other participants' contribution. Therefore, sequence analysis is, in itself, a valuable contribution to the methodology of patient-provider communication studies.

In this issue, an important paper is published on the analysis of verbal interaction sequences in dyadic clinical communication [7]. In that paper, different methods of sequence analysis are presented, together with their strengths and flaws and examples of their use, which will provide much guidance for researchers who are interested in applying sequence analysis to 
Bensing, J., Verheul, W. Towards a better understanding of the dynamics of patient provider interaction: the use of sequence analysis. Patient Education and Counseling: 2009, 75(2), 145146

their own data. By presenting the various methods in a comprehensive, critical review, the authors give a good idea of the current state of the art in this fast developing area. It shows a rich arsenal of new tools, waiting for us to explore. Hopefully it will also help to prevent common pitfalls in sequence analysis, such as ignoring the clustering of data within consultations, doctors and patients, addressed by Connor et al as the problem of heterogeneity [7]: we might find certain sequences in a consultation with one patient, but completely different ones in another. The authors also draws our attention to another problem which often remains an unrecognized problem in patient-provider interaction research: the problem of non-stationarity, which means that relations between variables can change during a consultation, dependent, for instance, on the phase of the consultation or on critical positive or negative incidents, earlier in the consultation. Using different words, this same point has recently been made by Suchman [8], when he stated that patient-provider interaction shows all the characteristics of a self-organizing, non-linear process, in which patterns tend to replicate themselves but small differences, can sometimes escalate rapidly into entirely new patterns, depending upon the diversity and the responsiveness in the interaction. This means that the different elements in clinical communication do not emerge as a simple function of the participants. Instead the emerging pattern is constantly influenced by the preceding communication. Simple linear sequential models might fail to capture the complexity of those continuous feedback relations. Nonlinear models, as are developed within complexity theory might be better equipped to deal with these longer stretches of interaction. But the application of these nonlinear models, fascinating as they are, still seems to be a long way from application in the field of patient-provider interaction. So, all in all, the paper by Connor et al. shows us the direction we ought to go, but also that the road to go is still long and difficult. Hopefully, it gives enough inspiration to a generation of researchers which will put these ideas and techniques to an empirical test. This really could help the field forward.

One of the most important messages of this paper is that we should not limit our research questions to the ones we can address with the statistical methods of analysis known to us. It really should be the other way around, as was argued before [9]. By making clear hypotheses on how the different elements and processes in clinical communication are influenced, we can make more realistic models, which subsequently can be used to test our hypotheses on the micro dynamics in clinical communication. Connor et al. show in their paper that researchers still seem to be guided by the availability of (new) statistic techniques rather than by their theories on the course of patient-provider interaction. This is clearly apparent in the relative abundance of papers focusing on short term processes in clinical communication, while papers researching longer, more complicated patterns are very rare. The authors start with a solution for this issue by looking over the boundaries of the field of clinical communication to researchers in other fields and the methods they use for analysing sequences. Healthcare communication researchers should do this more often, for much can be learned from other disciplines in which sequence analyses are often applied, for instance social psychology, mathematics and econometrics.

Of course there will also remain a need for descriptive, frequency-based studies, for instance when researchers want to compare health communication patterns in different patient groups, disease groups, disciplines, health care settings, or countries. But sequence analysis seems to be a new and challenging way of analyzing patient provider communication. Hopefully, the paper by Connor et al. in this issue of Patient Education and Counseling gives researchers inspiration as well as tools to fully explore the potential of sequence analysis for studying the dynamics of patient-provider interaction. And furthermore - it cannot be stressed enough (to quote Cato: "Ceterum censeo Carthaginem delendam esse"), future research should really combine quantitative and qualitative approaches to a greater extent than has been the case to date [5]. 
Bensing, J., Verheul, W. Towards a better understanding of the dynamics of patient provider interaction: the use of sequence analysis. Patient Education and Counseling: 2009, 75(2), 145146

\section{REFERENCES}

[1] Inui TS, Carter WB. Outcome based doctor-patient interaction analysis. I. Comparison of techniques. Medical Care 1982;20:535. Problems and prospects for health services research on provider-patient communication. Medical Care 1985;23:521-38.

[2] W.B. Carter and T.S. Inui, Outcome based doctor-patient interaction analysis. II. Identifying effective provider and patient behaviour, Medical Care 20 (1982), pp. 550-566

[3] T.S. Inui and W.B. Carter, Problems and prospects for health services research on provider-patient communication, Medical Care 23 (1985), pp. 521-538.

[4] D.L. Roter, S.M. Larson, M.C. Beach and L.A. Cooper, Interactive and evaluative correlates of dialogue sequence: a simulation study applying the RIAS to turn taking structures, Patient Educ Counsel 71 (2008), pp. 26-33.

[5] C. Zimmermann, L. Del Piccolo and A. Finset, Cues and concerns by patients in medical consultations: A literature review, Psychol Bull 133 (3) (2007), pp. 438-463.

[6] A. Abbot, Sequence analysis. New methods for old ideas, Annu. Rev. Sociol. 21 (1995), pp. 93-113.

[7] M. Connor, I. Fletcher and P. Salmon, The analysis of verbal interaction sequences in dyadic clinical communication: A review of methods, Patient Educ. Counsel. 75 (2009), pp. 169-177.[8] A. Suchman, A new theoretical foundation for relationship-centered care complex responsive processes of relating, J Gen Intern Med 21 (2006), pp. S40-44.

[9] Bensing JM. Implicit theories in doctor-patient communication. In: Bensing JM. Doctorpatient communication and the quality of care. An observation study into affective and instrumental behaviour in general practice. NIVEL, Utrecht/Rotterdam; 1991. 